\title{
Cerebral Venous Sinus Thrombosis in a Patient With Graves' Disease
}

\author{
Maren Hieber ${ }^{\mathrm{a}, \mathrm{b}}$, Johann Lambeck ${ }^{\mathrm{a}}$
}

\begin{abstract}
Cerebral venous sinus thrombosis (CVST) constitutes a small proportion of stroke. Its risk factors include hypercoagulability of various causes. We report the case of a 54-year-old woman in whom thrombosis of the left transverse and sigmoid sinus was diagnosed. The extended etiological workup revealed hyperthyroidism, and further analysis showed clinical results consistent with Graves' disease and decreased levels of protein C. A small number of similar cases - of both the general association of hyperthyroidism and CVST and the additional finding of low protein $\mathrm{C}$ - have been described in the literature, so that our case further supports the likely association of hyperthyroidism and hypercoagulability.
\end{abstract}

Keywords: Cerebral venous sinus thrombosis; Graves' disease; Hypercoagulability; Hyperthyroidism; Protein C deficiency

\section{Introduction}

Cerebral venous sinus thrombosis (CVST) is a rare disease accounting for less than $1 \%$ of all strokes. Due to its broad and unspecific spectrum of symptoms, it is often diagnosed with delay, although the widespread use of neuroimaging, especially magnetic resonance imaging (MRI) and MR venography, has reduced the time required to establish diagnosis. The sources or causes of CVST are varied and can include cancer, genetic or acquired prothrombotic disorders, hematological diseases, vasculitis or other systemic inflammatory disorders, as well as local causes (arteriovenous malformations, trauma, infections of the central nervous system (CNS) or neighboring structures and brain tumors) [1]. However, even with extensive diagnostic testing, a significant number of CVST still have an

Manuscript accepted for publication October 10, 2016

aDepartment of Neurology, University Medical Center Freiburg, Freiburg im Breisgau, Germany

${ }^{\mathrm{b}}$ Corresponding Author: Maren Hieber, Department of Neurology, University Medical Center Freiburg, Breisacher Str. 64, 79106 Freiburg, Germany.

Email: maren.hieber@uniklinik-freiburg.de

doi: http://dx.doi.org/10.14740/jem378w unclear etiology.

Graves' disease is an autoimmune disorder causing hyperthyroidism, goiter, ophthalmopathy and occasionally myxedema. Its diagnosis is based on the presence of thyroid-stimulating immunoglobulin (TSI), which stimulates the production of thyroid hormones and hence represents the pathogenetic component of the disease.

Several studies report an association between hyperthyroidism and hypercoagulability via elevated plasma levels of factor VIII, reduced levels of antithrombotic protein $\mathrm{C}$ and $\mathrm{S}$ [2], and/or accelerated platelet plug formation via elevated levels of von Willebrand factor [3].

\section{Case Report}

We report the case of a 54-year-old woman in whom CVST was detected in the left transverse and sigmoid sinus, accompanied by congestive parenchymal hemorrhage and subdural hematoma. In addition, lab tests at admission revealed manifest hyperthyroidism, which, after further workup, could then be attributed to Graves' disease.

The patient was hospitalized due to progressive holocephal headache with frontal accentuation and impaired concentration over 4 days. At admission, the patient additionally reported heart palpitations, nausea and diarrhea during the previous 2 weeks. Clinical examination showed compromised alertness and non-fluent aphasia, while electrocardiography (ECG) showed tachyarrhythmia absoluta. Cranial MRI and MR venography revealed CVST of the left transverse and sigmoid sinus combined with congestive intracerebral and subdural hemorrhage (Fig. 1). Lab tests revealed manifest hyperthyroidism (thyroid-stimulating hormone $(\mathrm{TSH})<0.014 \mu \mathrm{U} /$ $\mathrm{mL}$, triiodothyronine $\left(\mathrm{T}_{3}\right) 25.84 \mathrm{pmol} / \mathrm{L}$, and thyroxine $\left(\mathrm{T}_{4}\right)$ $61.3 \mathrm{pmol} / \mathrm{L}$ ), and further tests showed results that were consistent with Graves' disease (TSI 26.84 IU/L, thyroid peroxidase antibodies (anti-TPO) 82.0 IU/L, hypervascularization of thyroid tissue, but no local venous compression as seen via sonography) (Table 1 and Fig. 2). Lumbar puncture and tests of cerebrospinal fluid (CSF) showed no signs of septic CVST, but since opening pressure was slightly elevated $\left(27 \mathrm{cmH}_{2} \mathrm{O}\right.$, norm 6 - $20 \mathrm{cmH}_{2} \mathrm{O}$ ), $15 \mathrm{~mL} \mathrm{CSF}$ was drained. In the extended search for predisposing factors, a slightly decreased level of functional protein $\mathrm{C}$ was found. 


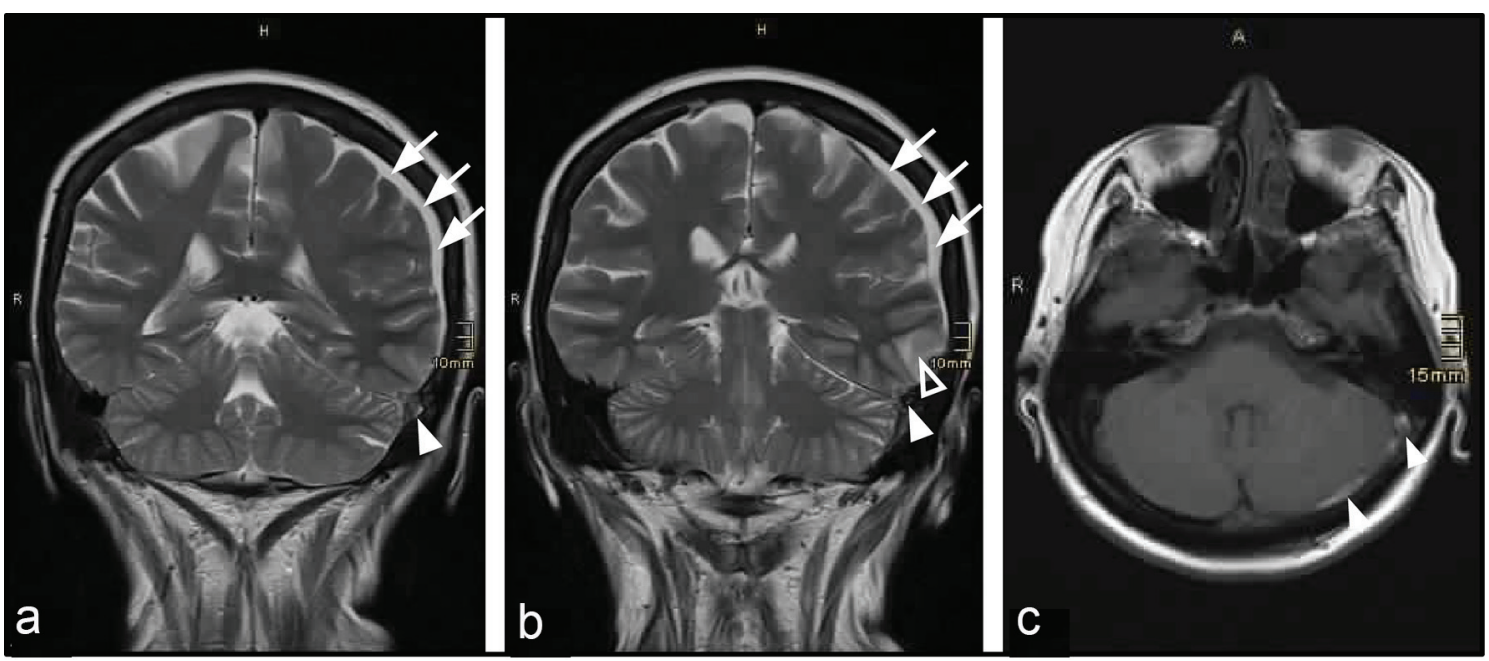

Figure 1. Detection of CVST by cranial MRI. (a, b) T2-weighed MRI, coronal section. (c) Gadolinium-enhanced T1-weighed image, axial section. Filled arrowheads show thrombus in the left transverse and sigmoid sinus. Blank arrowhead shows left temporal intracerebral hemorrhage. Arrows show left parietal subdural hematoma.

Beyond parenteral anticoagulation (for therapy of CVST) and drug-based control of heart frequency by metoprolol, thyrostatic therapy with methimazole was initiated. Due to the initially fluctuating clinical presentation with recurrent episodes of non-fluent aphasia and decreased vigilance, recurrent focal epileptic seizures were considered in the differential diagnosis. Electroencephalography (EEG) showed focal slowing on the left side, but no epileptic potentials. Nevertheless, anti-convulsive therapy was initiated with levetiracetam and continuation for 3 months was recommended. Permanent continuation of (oral) anti-coagulation was recommended, based on the additionally detected atrial fibrillation.

Under anticoagulant, anticonvulsive, thyrostatic and symptomatic analgesic therapy, the patient recovered well within 2 weeks and, upon discharge, only suffered from mild amnestic aphasia and mild nausea. Levels of thyroid hormones normalized under thyrostatic therapy (Table 1).

\section{Discussion}

Our case of CVST and hyperthyroidism provides further support for the hypothesis that hyperthyroidism is associated with a hypercoagulable state [4-6]. While Siegert et al proposed a pathogenetic mechanism based on local venous compression by large goiter [7], our case with normal thyroid size does not corroborate this finding. Another clinical study demonstrated that the postulated association between hyperthyroidism and prothrombotic state/hypercoagulability can be supported by measurable blood parameters [8]. In particular, the reported dependency of protein $\mathrm{C}$ levels on thyroid hormones levels is in line with the present case, where a decreased level of functional protein $\mathrm{C}$ was measured during phases of high $\mathrm{T}_{3} / \mathrm{T}_{4}$ levels. Similar constellations (hyperthyroidism and protein $\mathrm{C}$ deficiency) were shown in the reported cases of De Schryver et al [9], Nagumo et al [10] and $\mathrm{Ra}$ et al [11]. In case of the former, lupus anticoagulant was detected as an additional prothrombotic factor. Consistent with the pathogenetic mechanism proposed by Siegert et al, Ra et al additionally described a large goiter in their patient as a potential hemodynamic factor, i.e. local compression of the jugular vein and consecutive impaired cerebral venous drainage. Besides the potential dependency of protein $\mathrm{C}$ on thyroid hormones, the decreased level of protein $\mathrm{C}$ could alternatively be caused by higher metabolism of protein $\mathrm{C}$ due to thrombosis. In either case, we consider the decreased level of protein $\mathrm{C}$ an acquired transient

Table 1. Lab Parameters Indicative of Graves' Disease, and Their Course During Therapy

\begin{tabular}{llllll}
\hline Parameter & Reference & Admission & Course 1 & Course 2 & Discharge \\
\hline $\mathrm{TSH}(\mu \mathrm{U} / \mathrm{mL})$ & $0.27-4.20$ & $<0.014$ & & & $<0.014$ \\
$\mathrm{~T}_{3}(\mathrm{pmol} / \mathrm{L})$ & $3.4-6.8$ & 25.84 & 7.81 & 5.92 & 5.97 \\
$\mathrm{~T}_{4}(\mathrm{pmol} / \mathrm{L})$ & $10.6-22.7$ & 61.3 & 29.8 & 20.9 & 14.5 \\
$\mathrm{TSI}(\mathrm{IU} / \mathrm{L})$ & $<1.75$ & 26.84 & & & \\
Anti-TPO $(\mathrm{IU} / \mathrm{mL})$ & $<34$ & 82.0 & & & \\
Functional protein C $(\%)$ & $70-134$ & 47 & & & \\
\hline
\end{tabular}

Course 1: 4 days after starting thyrostatic therapy. Course 2: 7 days after starting thyrostatic therapy. Discharge: 12 days after starting thyrostatic therapy. 


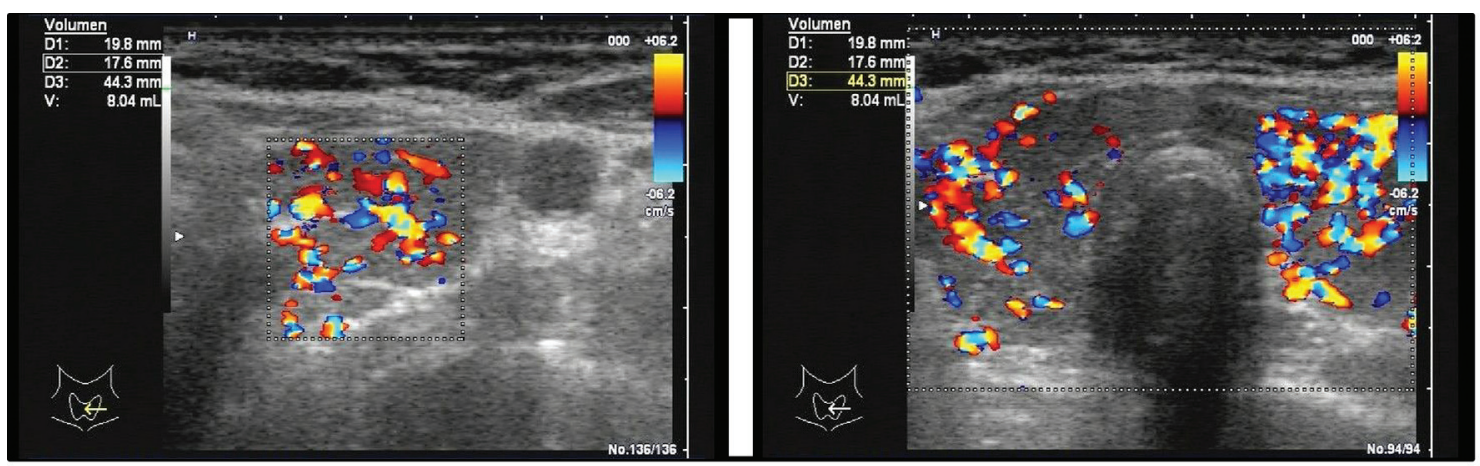

Figure 2. Sonography of the thyroid gland shows hyperperfusion of the thyroid parenchyma, consistent with the diagnosis of Graves' disease. Volume measurement revealed normal thyroid size ( $v=16.6 \mathrm{~mL}$, norm: up to $18 \mathrm{~mL})$.

feature, rather than a distinct primary cause. However, it could represent a pathogenetic factor in patients with hyperthyroidism and thrombosis.

Further studies at both the biochemical/molecular and clinical level are needed to better understand the general pathogenesis of thrombosis in patients with hyperthyroidism, and to identify the optimal diagnostic and therapeutic approaches.

\section{Acknowledgments}

We thank Dr. Sandra Dieni for helpful comments on the manuscript and Dr. Felix Hieber for revising the manuscript.

\section{Author Contributions}

M. Hieber and J. Lambeck were the treating physicians of the patient. M. Hieber wrote and edited the manuscript. J. Lambeck reviewed and edited the manuscript.

\section{References}

1. Bousser MG, Ferro JM. Cerebral venous thrombosis: an update. Lancet Neurol. 2007;6(2):162-170.

2. Stuijver DJ, van Zaane B, Romualdi E, Brandjes DP, Gerdes VE, Squizzato A. The effect of hyperthyroidism on procoagulant, anticoagulant and fibrinolytic factors: a systematic review and meta-analysis. Thromb Haemost. 2012;108(6):1077-1088.

3. Homoncik M, Gessl A, Ferlitsch A, Jilma B, Vierhap- per H. Altered platelet plug formation in hyperthyroidism and hypothyroidism. J Clin Endocrinol Metab. 2007;92(8):3006-3012.

4. Pekdemir M, Yilmaz S, Ersel M, Sarisoy HT. A rare cause of headache: cerebral venous sinus thrombosis due to hyperthyroidism. Am J Emerg Med. 2008;26(3):383 e381382.

5. Hermans E, Marien P, De Deyn PP. Sinus sigmoideus thrombosis secondary to graves' disease: a case description. Case Rep Neurol. 2011;3(3):203-209.

6. Mouton S, Nighoghossian N, Berruyer M, Derex L, Philippeau F, Cakmak S, Honnorat J, et al. Hyperthyroidism and cerebral venous thrombosis. Eur Neurol. 2005;54(2):78-80.

7. Siegert CE, Smelt AH, de Bruin TW. Superior sagittal sinus thrombosis and thyrotoxicosis. Possible association in two cases. Stroke. 1995;26(3):496-497.

8. Horne MK, 3rd, Singh KK, Rosenfeld KG, Wesley R, Skarulis MC, Merryman PK, Cullinane A, et al. Is thyroid hormone suppression therapy prothrombotic? J Clin Endocrinol Metab. 2004;89(9):4469-4473.

9. De Schryver EL, Hoogenraad TU, Banga JD, Kappelle LJ. Thyrotoxicosis, protein $\mathrm{C}$ deficiency and lupus anticoagulant in a case of cerebral sinus thrombosis. Neth $\mathrm{J}$ Med. 1999;55(4):201-202.

10. Nagumo K, Fukushima T, Takahashi H, Sakakibara Y, Kojima S, Akikusa B. [Thyroid crisis and protein C deficiency in a case of superior sagittal sinus thrombosis]. Brain Nerve. 2007;59(3):271-276.

11. Ra CS, Lui CC, Liang CL, Chen HJ, Kuo YL, Chen WF. Superior sagittal sinus thrombosis induced by thyrotoxicosis. Case report. J Neurosurg. 2001;94(1):130-132. 